\title{
Considering the Right to Enjoy the Benefits of Scientific Progress and Its Applications As a Cultural Right
}

\author{
A Change in Perspective
}

\author{
Mylène Bidault
}

Whether the right to enjoy the benefits of scientific progress and its applications is a cultural right is a fundamental question and far from a matter of mere form.

A positive answer invites us to reconsider the meaning of, and to give full scope to, the "right to science" increasingly invoked today in academic and NGO circles, as well as by human rights mechanisms. Considering the right to enjoy the benefits of scientific progress and its applications as a cultural right means understanding it as an integral part of the rights that enable people to access and make use of the most diverse sources of knowledge and the cultural resources most meaningful for them. It also means enabling people to contribute to those resources, and to use them for the benefit of their own dignity and development.

Consequently, this right is more than simply a right to science. The time has come to speak of a much more substantial "right to participate in scientific life" and to see it as a component of the right to participate in cultural life. This right enables everyone to have access to, and contribute to, the development of science, and to exercise his or her critical and scientific spirit in everyday life.

This does not mean that everyone ought suddenly to become a high-level scientific researcher; but rather, that everyone can aspire to be a researcher in his or her own spheres of interest, using and deploying knowledge for the benefit of his or her own development. Herein lies the eminently human and emancipatory dimension of this right.

\footnotetext{
This chapter is taken from a presentation made during the Day of General Discussion on the right to enjoy the benefits of scientific progress and its applications and the other provisions of article 15 of the International Covenant on Economic, Social and Cultural Rights, on the relationship between science and economic, social and cultural rights, organized on October 9, 2018 by the Committee on Economic, Social and Cultural Rights. I would like to thank Patrice Meyer-Bisch for our discussions on this topic, which were very helpful to me. The views expressed in this chapter are personal and do not necessarily reflect those of the Office of the High Commissioner for Human Rights.
} 


\subsection{PURE FORMAL REASONS}

Several elements, both in international human rights treaties and declarations, as well as in the practice of monitoring mechanisms, call for the right to enjoy the benefits of scientific progress and its applications to be considered as a cultural right.

In the first place, the right to enjoy the benefits of scientific progress and its applications is often found juxtaposed with the right to take part in cultural life in universal and regional texts. In particular, it is to be found in Article 27 of the Universal Declaration of Human Rights (UDHR) and Article 15 of the International Covenant on Economic, Social and Cultural Rights (ICESCR), which are usually considered to set out cultural rights. ${ }^{1}$

Furthermore, the resolutions of the Human Rights Council establishing and subsequently renewing the mandate of the Special Rapporteur in the field of cultural rights expressly mention the right to enjoy the benefits of scientific progress and its applications as an integral part of the Rapporteur's mandate. The Special Rapporteur has devoted an entire thematic report to this right. ${ }^{2}$ Member States of the Council seem to have naturally considered, by consensus, that the right to enjoy the benefits of scientific progress and its applications is a cultural right.

\subsection{SUBSTANTIVE REASONS}

But these elements are ultimately only formal indications. The argument that the right to enjoy the benefits of scientific progress and its applications should be considered as a cultural right is supported by far more substantial grounds. Its proximity in the texts to the right to take part in cultural life seems to be no coincidence. It appears, at least, to be the result of a particularly accurate intuition on the part of the authors of the founding texts. And, as will be explained below, it makes it possible today to deploy the scope of this right in a far more powerful and significant manner.

When one looks more closely at the structure of Article 15 of ICESCR, one understands that, when taken as a whole, it is the universal right of access to culture and science that is protected by this provision, as Farida Shaheed, the first Special Rapporteur in the field of cultural rights, has emphasized. ${ }^{3}$ The right is accompanied by correlative obligations on States to respect and protect creative freedoms; to respect and protect the moral and material interests resulting from scientific, literary or artistic productions; to ensure the conservation, development and diffusion of science and culture; and to develop international contacts and cooperation in these fields.

1 Many other provisions in international treaties do protect cultural rights. For an in-depth overview, see Mylène Bidault, La protection internationale des droits culturels, Brussels, Bruylant, 2009, 559 pages.

$2 \mathrm{~A} / \mathrm{HRC} / 20 / 26$, The right to enjoy the benefits of scientific progress and its applications.

$3 \mathrm{~A} / \mathrm{HRC} / 20 / 26, \mathbb{1} 17$. 
But there is an even more fundamental reason for considering the right to enjoy the benefits of scientific progress and its applications as a cultural right: science is part of culture.

\subsubsection{The Scientific Field As an Integral Part of the Cultural Field}

The right to take part in cultural life necessarily implies a right to take part in scientific life, which must be understood as legally based on both Article 15(1)(a) of the ICESCR (right to take part in cultural life) and Article 15(1)(b) (right to enjoy the benefits of scientific progress and its applications). The second element is in fact a specification of the first one.

Let me explain what is meant by "cultural field." The 2007 Fribourg Declaration on Cultural Rights proposes a definition of "culture" as covering "the values, beliefs, convictions, languages, knowledge and the arts, traditions, institutions and ways of life through which a person or group expresses their humanity and the meanings that they give to their existence and to their development" (Article 2). ${ }^{4}$

This definition has been a major source of inspiration for both the Committee on Economic, Social and Cultural Rights (hereinafter the Committee) and the Special Rapporteur in the field of cultural rights throughout her work.

The cultural field is therefore very broad, as reflected in the list inserted in the Fribourg Declaration: values, beliefs, convictions, languages, knowledge, arts, traditions, institutions and ways of life. In its General Comment No. 21 on the right to take part in cultural life, the Committee defined what was covered by "cultural life" and added elements to this list, including in particular "methods of production or technology" (\$13). The Committee stressed that "culture is a broad, inclusive concept encompassing all manifestations of human existence" $(\mathbb{1 1})$. It is, again according to the Committee, "an interactive process whereby individuals and communities, while preserving their specificities and purposes, give expression to the culture of humanity" $(\$ 12)$.

The Committee has further clarified that science is a part of culture in its new General Comment 25 (2020) on science and economic, social and cultural rights. ${ }^{5}$ A whole paragraph 10 is devoted to this aspect. Reiterating that culture is an inclusive

4 The Fribourg Declaration on cultural rights is a civil society document adopted in 2007. It brings together and unfolds cultural rights scattered throughout international texts. It is the result of consultations and work carried out by the members of the Fribourg Group, inter alia with UNESCO, the Council of Europe and the International Organization of the Francophonie and has inspired much work at the international and national levels on cultural rights. It has been supported by more than fifty national and international experts, including members of the CESCR and Special Rapporteurs at that time. It has now been translated into more than ten languages. For more information, please see Patrice Meyer-Bisch and Mylène Bidault, Déclarer les droits culturels, Commentaire de la Déclaration de Fribourg, Schulthess, Bruxelles, Genève, Zurich, Bâle, Bruylant, 154 pages (freely available on Academia); https://droitsculturels.org/observatoire/la-declaration-de-fribourg/; or simply use an internet search engine to see the multiple uses of the Declaration by various actors.

5 E/C.12/GC/25. 
concept encompassing all manifestations of human existence, the Committee added that "Cultural life is therefore larger than science, as it includes other aspects of human existence; it is, however, reasonable to include scientific activity in cultural life. Thus, the right of everyone to take part in cultural life includes the right of every person to take part in scientific progress and in decisions concerning its direction."

This does not mean that the field of culture is a great pool of conceptual magma in which all human endeavors merge and agglomerate. The specificity of the scientific field, that is, what makes it an element apart from the other elements of culture, must be defined (see Section 8.3.2.below).

\subsection{SIGNIFICANT IMPACTS}

When considering why the question of whether the right to enjoy the benefits of scientific progress and its applications is a cultural right is important, one might be tempted to ask what difference such an understanding actually makes. Is this a purely theoretical discussion without practical implications, or are there important consequences to understanding the right to enjoy the benefits of scientific progress and its applications as a cultural right? Framing the question this way will help evolve our understanding of the content of the right.

\subsubsection{What Is a Cultural Right?}

Important elements of definition have been provided by the Special Rapporteur in the field of cultural rights, who has drawn inspiration from the work of the Committee and its General Comment No. 21, as well as from the work of the Fribourg Group. Several elements have been identified:

- Cultural rights are the rights of persons "to develop and freely express their humanity, their world view and the meaning they give to their existence and development."

- People do this "through, inter alia, values, beliefs, convictions, languages, knowledge and the arts, institutions and ways of life."

- Cultural rights also protect "access to cultural heritage as important resources enabling such identification and development processes."6

Cultural rights are therefore a broad set of freedoms and rights of access to and participation in resources. They protect:

- The freedom of persons, alone or in community with others, to choose and build their identity, world view and the meaning they give to their humanity;

$6 \mathrm{~A} / \mathrm{HRC} / 14 / 36, \int 9 ; \mathrm{A} / 67 / 287$ on the enjoyment of cultural rights by women on an equal basis with men, $\$ 7 ; \mathrm{A} / \mathrm{HRC} / 31 / 59(2016), \mathbb{} 7$. 
- The freedom of persons, alone or in community with others, to participate in cultural life while expressing that identity, world view or humanity; and

- The rights of persons, alone or in community with others, to have access to the resources necessary for the development and fulfilment of their identities, world views and humanity, which implies the right to know, understand, discuss and transmit these resources, to make use of them and to participate in their development.

"Knowledge" in the broadest sense enables people in the same way as "beliefs" and "convictions" do. Knowledge enables individuals to build their identity, humanity and worldview, to forge their responses to adversity, to conceive of the world, and to conceive of themselves as part of this world.

It is sometimes difficult to separate beliefs from knowledge, whether these be individual or collective. Moreover, knowledge is not exclusively of a scientific nature - knowledge exists in the field of arts, for example, and there exist even more diverse forms of knowledge. It is from all these resources that individuals draw in order to develop themselves, arranging such resources at the individual level in a way that is very particular to them: to express their creativity, to influence their living conditions, or to overcome an ordeal such as an illness or a disaster. It is through these resources that people can "aspire" to a better future by identifying the elements they consider essential for a life with dignity.

Thus, as Farida Shaheed has strongly expressed:

The link between the right to science and the right to culture can be further understood with regard to people's ability to "aspire." A growing body of literature suggests that the ability to aspire - namely, to conceive of a better future that is not only desirable but attainable - is an important cultural capability that needs to be supported and developed, especially among the marginalized and vulnerable. Aspirations embody people's conceptions of elements deemed essential for a life with dignity. Never a mere individual exercise, aspirations are informed by, and in turn inform, communities of shared cultural values and draw upon cultural heritage, including accessible, accumulated scientific knowledge. New scientific knowledge and innovations increase available options, thereby strengthening people's capacity to envisage a better future for which access to specific technologies may sometimes be pivotal. ${ }^{7}$

\subsubsection{The Specificity of the Scientific Field Within the Cultural Field}

One important question is to define the specificity of scientific resources within this set of essential resources: what makes them different from other cultural resources.

$7 \mathrm{~A} / \mathrm{HRC} / 2 \mathrm{O} / 26$, 2O, in reference to Arjun Appadurai, "The Capacity to Aspire: Culture and the Terms of Recognition," in Culture and Public Action, Vijayendra Rao et Micheal Walton (eds.), Stanford University Press, 2004. 
Article 15(1)(b) requires that this specificity be developed. Some elements of this are provided, again, in the report by Farida Shaheed:

As for other cultural rights, a prerequisite for implementing the right to enjoy the benefits of scientific progress and its applications is ensuring the necessary conditions for everyone to continuously engage in critical thinking about themselves and the world they inhabit, and to have the opportunity and wherewithal to interrogate, investigate and contribute new knowledge with ideas, expressions and innovative applications, regardless of frontiers. More precisely, the right to participate in cultural life entails ensuring conditions that allow people to reconsider, create and contribute to cultural meanings and manifestations in a continuously developing manner. The right to enjoy the benefits of science and its applications entails the same possibilities in the field of science, understood as knowledge that is testable and refutable, including revisiting and refuting existing theorems and understandings. ${ }^{8}$

The Committee, in its General Comment, takes a similar approach, cautious to refer to the specificity of science, and referring to the definition offered in the 2017 UNESCO Recommendation on Science and Scientific Researchers. ${ }^{9}$

To develop themselves, therefore, people draw on cultural heritage, including "accessible scientific knowledge," which is extremely diverse; and thus we should not be afraid to speak of "scientific diversity" as an integral part of "cultural diversity." There is no such thing as science on the one hand and culture on the other. And since we talk about cultures today in the plural form, we must also talk about sciences, given the great diversity of scientific disciplines and traditions. All of them have their contribution to make in terms of the way in which we face our world.

For example, the various medical traditions are valuable, ranging from the very Cartesian vision, which understands the human person as a machine that can be examined and healed piece by piece, to the most holistic visions that understand the human person in its inseparable dimension body-mind, in permanent relationship with its environment. This is what many non-Western approaches teach us, or reteach us. To lose this diversity would be an appalling impoverishment.

We must also be careful not to restrict the scope of what we mean by scientific, at the risk of favoring some scientific traditions to the detriment of others and thereby preventing potentially valuable and culturally diverse contributions. We must not forget too that behind the scenes of debates on what is or is not science lie powerful political dynamics and asymmetries as well as significant economic stakes. There are fierce debates, for instance, over the question of which medical drugs will or will not be covered by medical insurances, a major economic issue for 
pharmaceutical companies. Attacks on homeopathy do not seem to be unrelated to these issues.

\subsection{FROM THE RIGHT TO ENJOY THE BENEFITS OF SCIENTIFIC PROGRESS AND ITS APPLICATIONS TO THE RIGHT TO PARTICIPATE IN SCIENTIFIC LIFE}

One matter considered by the Committee during its discussions on the text of the General Comment concerned whether it would be appropriate to speak of a "right to science," rather than of a "right to enjoy the benefits of scientific progress and its applications." It is true that the expressions "right to culture" and "right to science" are often used to refer to the rights contained in Article 15 of the ICESCR.

These expressions, which are also sometimes used by the Special Rapporteur in the field of cultural rights, are intended to give full scope to the rights set out in Article 15, which, it should be recalled, enshrines a universal, fundamental right of participation in and access to culture, including science. This was the approach adopted by Farida Shaheed, who also found that "right to science" was a strong formula that was more striking.

A similar proposal had been made by the Committee in a Draft General Comment that it circulated for comments on January 20, 2020. A whole paragraph 89 , at the end of the document, proposed to use a "single broad concept named the human right to science." However, that proposal was not retained in the final version of the General Comment.

Indeed, if we are not careful, these expressions ("right to culture," "right to science") can misrepresent the content of the rights and give a truncated and incomplete vision of them. On the one hand, with such expressions, culture remains separated from science. Science, understood as "verifiable and testable knowledge," must not be situated in opposition to "culture," but to "belief" (although there are some grey areas). Furthermore, we still speak of "culture" (which culture?) and "science" in the singular form, even though we are in front of what should be called "cultural" and "scientific diversity."

Finally, this risks reducing the right to the notion of access only (whether to culture or to science). While access to both culture and science is obviously extremely important, in its General Comment No. 21, the Committee considered the right to participate in cultural life as concerning rights to participate in, contribute to, and have access to cultural life. A reductionist access-based approach risks reducing the rights-holder conceptually to a "consumer" of rights, whereas the spirit of human rights demands that he or she should be understood as a citizen and actor, an agent of his or her own rights. 
If these expressions are used, then they must be defined so as to avoid these pitfalls, emphasizing not only the crucial issue of access, but also participation and contribution, which are no less fundamental.

\subsubsection{Towards a Right to Participate in Scientific Life}

The Committee, in General Comment No. 25, has chosen not to refer to a "right to science." It underlined that "The right enshrined in article 15 (1) (b) encompasses not only a right to receive the benefits of the applications of scientific progress, but also a right to participate in scientific progress. Thus, it is the right to participate in and to enjoy the benefits of scientific progress and its applications." The latter expression is used by the Committee throughout General Comment No. $25 .{ }^{10}$

It is useful, as the Committee did, to read Article 15 of the ICESCR in conjunction with Article 27 of the UDHR, which wording better corresponds to the nature of the right as a cultural right. The Universal Declaration sets out a right to "share in scientific advancement and its benefits." The use of the phrase "share in" unveils the cultural element of the right, and gives context to its placement within a provision rooted in wider cultural considerations. Therefore, an ambitious approach is to understand the provision as protecting a right to participate in scientific "life," modeled on the right to participate in cultural life. This gives us a fresh and valuable perspective on what the right truly means.

Clearly there are surface-level criticisms that can be leveled against such formula. In particular, not everyone can be a scientific researcher. But that would be a restrictive, even reductionist, reading of the right if formulated this way. Life is complex and multi-faceted and we all participate in different ways. A right to participate in scientific life does, therefore, not imply that we all ought to become high-level researchers. Rather it means that we might become researchers in our own fields and in relation to our own concerns and aspirations; that we use knowledge and refine it for our own personal development.

Farmers who cultivate their land, for example, must have access to all relevant data and information in order to eke from that land the greatest possible yield. That data is collated, analyzed, tested, and applied; processes are improved. The cycle is iterated to meet new challenges or obstacles. Farmers are not mere performers implementing guidelines and instructions manuals. They are participants, in the fullest sense of the word: observing, being creative, practicing science, adapting it, improving it. Let us draw a parallel, this time, with the right to artistic freedom: the question is not for each person to develop into a locally or world-renowned artist, but to be able to enjoy the artistic experience, for his or her own development; to be creative and to contribute, in one's own ways, to cultural life. 
There are many advantages to talking about participation in scientific life. It enables an understanding that cultural life is multifaceted, with religious, artistic, scientific and family dimensions, for example, which all are key to the development and fulfilment of people. These facets are interrelated. All cultural freedoms, including scientific freedoms, enable the emergence of a critical spirit, the imagining of possibilities, and individual and collective emancipation.

For here we find ourselves at the heart of individual freedoms. In many areas, for example in the field of the environment (think of global warming) or public health (think of sugar in food), it is a question of practicing critical thinking on a daily basis (I insist here on the term "practicing," which I will talk about later). Why do some people lie? Because there is a lack of scientific knowledge among the public. It is certainly not in the interest of those who dominate or manipulate to promote a right to participate in scientific life.

Thus, the meaning of this right is not limited to a right of access to material results or technologies (to a progress that would be a given, indisputable), but also includes a right of access to knowledge, and to conditions allowing the development of scientific and critical thinking. That is why there is a very strong link between the right to participate in cultural life and the rights to information and education. The issue is not only about teaching "scientific content." It is above all about providing references, knowledge and tools to enable people to make informed choices. It is about instilling curiosity and critical and scientific spirit, offering ways to develop one's thinking in order to be free and autonomous. It is about knowing that knowledge is verifiable and contestable. The right to education and the right to participate in scientific life both require that science education programs be systematically provided at all levels.

Participation in science also means emphasizing people's right and ability to access, use and improve cultural resources, including scientific resources, for their development and the implementation of their own rights.

Thus, for example, the person with a chronic illness needs to be able to access the best medical care available, while at the same time being put in a position to keep a critical mind, to decide for himself or herself on the care provided (understanding its side effects), to draw on knowledge to treat himself or herself, and to build his or her healing power on the basis of the traditions and beliefs that make sense to him or her. As underlined by the Committee, "States parties must guarantee everyone the right to choose or refuse the treatment they want with the full knowledge of the risks and benefits of the relevant treatment, subject to any limitations that meet the criteria of article 4 of the Covenant."11

This is why it would be useful to take up the triptych used in General Comment No. 21 to describe the content of the right to take part in cultural life: "participate, contribute, access." It could be improved and become "access, practice, contribute."

11 General Comment 25, para. 44. 
It is here that I return to the notion of "practice," which helps to emphasize that everyone participates by developing his or her daily practice.

\subsection{CONCLUSiON}

The inclusion of the right to share in the benefits of science within the main provisions of the UDHR and the ICESCR devoted to cultural rights is fundamental. For culture is also science. This is not to level the playing field and consider science to be of the same nature as a philosophical or religious conviction, practice or way of life. No, it does have a specificity, and must be understood as "verifiable and contestable knowledge," with "the possibility of revising and rejecting existing conceptions and theorems."

However, science is not above culture either, it is part of it. And it is from a multitude of cultural resources, including scientific resources, that people build their identity, their world view and their humanity. 